Д. И. Рыжов ${ }^{1}$, А-й П. Шугайло², А. В. Кендзера ${ }^{2}$, В. В. Инюшев ${ }^{1}$, А-р П. Шугайло ${ }^{1}$, Р. Я. Буряк ${ }^{1}$

${ }^{1}$ Государственный научно-технический центр по ядерной и радиационной безопасности, г. Киев, Украина ${ }^{2}$ Институт геофизики им. С. И. Субботина

Национальной академии наук Украины, г. Киев, Украина

\section{Применение современных}

международных подходов к оценке сейсмической опасности площадок АЭС Украины

Результаты воздействий мощных землетрясений на АЭС в Японии («Кашивазаки-Карива», «Фукусима-1») продемонстрировали, что уровни этих воздействий могут превышать принятые в проекте. В святи с этим рассматривается вопрос внедрения в Украине современных международных подходов к оценке сейсмической опасности площа док действующих АЭС на примере площадки Южно-Украинской АЭС

Ключевые слова: АЭС, землетрясение, сейсмичность, интенсивность, опасность, ускорения.

\section{Д. І. Рижов, О-й П. Шугайло, О. В. Кендзера, В. В. Інюшев,} О-р П. Шугайло, Р. Я. Буряк

Застосування сучасних міжнародних підходів до оцінки сейсмічної небезпеки майданчиків АЕС України

Результати впливів потужних землетрусів на АEC Японії («Кашивазакі-Каріва», “Фукусіма-1») засвідчили, що рівні цих впливів можуть перевищувати прийняті в проекті. Узв'язкуз цим розглядається питання впровадження в Україні сучасних міжнародних підходів до оцінки сейсмічної небезпеки майданчиків діючих АEC на прикладі майданчика Южно-Української АЕС.

Ключові слова: AEC, землетрус, сейсмічність, інтенсивність, небезпека, прискорення.

(C) Д. И. Рыжов, А. В. Кендзера, А-й П. Шугайло, В. В. Инюшев, А-р П. Шугайло, Р. Я. Буряк, 2013
A

томные электростанции Украины проектировались в 70-80-х годах прошлого столетия согласно действовавшим на то время нормативным документам и их требованиям по проведению исследований сейсмичности площадки строительства АЭС. Судя по отчетам о результатах доисследований сейсмичности площадок Хмельницкой АЭС [1] и Ривненской АЭС [2], в то время считалось, что землетрясения на древних платформах крайне редки, а если и возникают, то небольшой энергии, поэтому специальные исследования по оценке геолого-тектонических условий и сейсмической опасности площадок АЭС не проводились.

Последствия землетрясения на АЭС «КашивазакиКарива» (16.07.2007, Япония), а также аварийные события на АЭС «Фукусима-Даичи» (11.03.2011, Япония) в результате землетрясения и вызванного им цунами продемонстрировали, что уровни этих экстремальных воздействий могут превышать принятые в проекте значения [3, 4].

Работы по уточнению сейсмической опасности площадок расположения АЭС Украины предусмотрены «Комплексной сводной программой повышения уровня безопасности энергоблоков атомных электростанций» (КсППБ) и, в частности, мероприятием № 18102 «Внедрение систем сейсмологического мониторинга площадок АЭС». Для реализации данного мероприятия на всех площадках АЭС Украины должны быть выполнены сейсмологические наблюдения и до 2016 г. получены (уточнены) количественные параметры прогнозируемых сейсмических воздействий (пиковые ускорения, акселерограммы землетрясений, спектры ответа грунта). Эти параметры в дальнейшем будут использованы для переоценки сейсмостойкости зданий, сооружений, оборудования и трубопроводов энергоблоков АЭС по уточненным сейсмическим воздействиям, присущим конкретной площадке размещения станции.

Уточнение сейсмической опасности площадок, кроме организации системы сейсмологического мониторинга, предполагает также проведения ряда полевых исследований на региональном и субрегиональном уровне. Требования к проведению полевых исследований регламентированы типовой программой работ по оценке сейсмической опасности площадок строительства АЭС, приведенной в ныне действующем в Украине нормативном документе ПНАЭ Г-5-006-87 [5]. Однако данный документ не пересматривался с момента его издания (декабрь 1987 г.) и в настоящее время не в полной мере учитывает современный уровень знаний, приобретенный опыт и международную практику. Пересмотр ПНАЭ Г-5-006-87 [5] в настоящее время находится на завершающей стадии и выполнялся ГНТЦ ЯРБ [6], в результате чего разработан проект нормативно-правового акта (НПА) «Требования к сейсмостойкому проектированию и оценке сейсмической безопасности энергоблоков атомных станций».

Выполненный ГНТЦ ЯРБ анализ [6] показывает, что наиболее полно требования к определению сейсмичности площадок атомных станций отражены в новом документе МАГАТЭ SSG-9 [7], в котором, в частности, содержатся сведения относительно:

необходимых полевых исследований (геолого-тектонических и сейсмологических);

построения региональной сейсмотектонической модели; определения сейсмической опасности площадки (уровней колебаний грунта).

С учетом требований (рекомендаций) МАГАТЭ SSG-9 [7] сейсмическая опасность площадки АЭС должна оцениваться в соответствии со специальным проектом, который 
разрабатывается соответствующей группой экспертов в составе геологов, сейсмологов, геофизиков, историков, инженеров и других специалистов. Геологические, геофизические, геотехнические и сейсмологические исследования должны выполняться в четырех масштабах:

региональном (в радиусе около 300 км от площадки);

субрегиональном (в радиусе не меньше 25 км от площадки);

района расположения площадки (в радиусе не меньше 5 км от площадки);

территории самой площадки.

На основании результатов изысканий формируется база данных, которая содержит:

геологические данные территории для каждого масштаба изысканий;

сейсмологические данные, к которым относятся исторические данные о землетрясениях (по возможности за наибольший промежуток времени), инструментальные данные о землетрясениях, специфические инструментальные данные для конкретной площадки.

Сейсмологические данные собирают по всем землетрясениям в рассматриваемом регионе, для которого выполняются исследования, и по ним составляют соответствующий каталог землетрясений. Собирают и обрабатывают статистические и инструментальные данные о землетрясениях. Целью выполнения этих работ является разработка сейсмотектонической модели региона расположения площадки. Все сейсмогенные структуры, которые могут влиять на сдвиг грунта на площадке, а также разломы на площадке, должны быть включены в сейсмотектоническую модель. С учетом собранных данных выполняется оценка опасности колебаний грунта на площадке. Документ SSG-9 [7] содержит рекомендации по применению вероятностных и детерминистических методов анализа сейсмической опасности площадки ядерной установки.

Конечный этап сейсмогеологического исследования площадки АЭС - разработка, на основе полученных данных, проектных характеристик колебаний грунта на площадке (пиковых ускорений, акселерограмм, спектров ответа). Для максимального расчетного землетрясения (MP3) значение пикового ускорения грунта (Peak Ground Acceleration - PGA) должно приниматься не меньше $0,1 g$ (для горизонтальной составляющей землетрясения). Эти данные впоследствии должны использоваться для оценки сейсмостойкости зданий и сооружений АЭС, расчетов поэтажных акселерограмм и спектров ответа зданий и сооружений, оценки сейсмостойкости оборудования и трубопроводов.

Первой площадкой действующих АЭС Украины, для которой Институтом геофизики им. С. И. Субботина НАН Украины выполнены масштабные исследования ее сейсмической опасности с учетом современной международной практики, стала площадка Южно-Украинской АЭС. Ниже приведены основные этапы и результаты этих исследований.

По результатам оценки геолого-тектонических условий установлено, что наиболее тектонически-активными и потенциально опасными зонами вблизи площадки ЮжноУкраинской АЭС являются Тальновский, Первомайский и Центральные разломы. Ослабленными в тектоническом отношении зонами могут быть места пересечения названных разломов с Кишиневской и Одесской зонами разрывных нарушений северо-восточного направления. Строение среды под реакторными отделениями энергоблоков №№ 1,

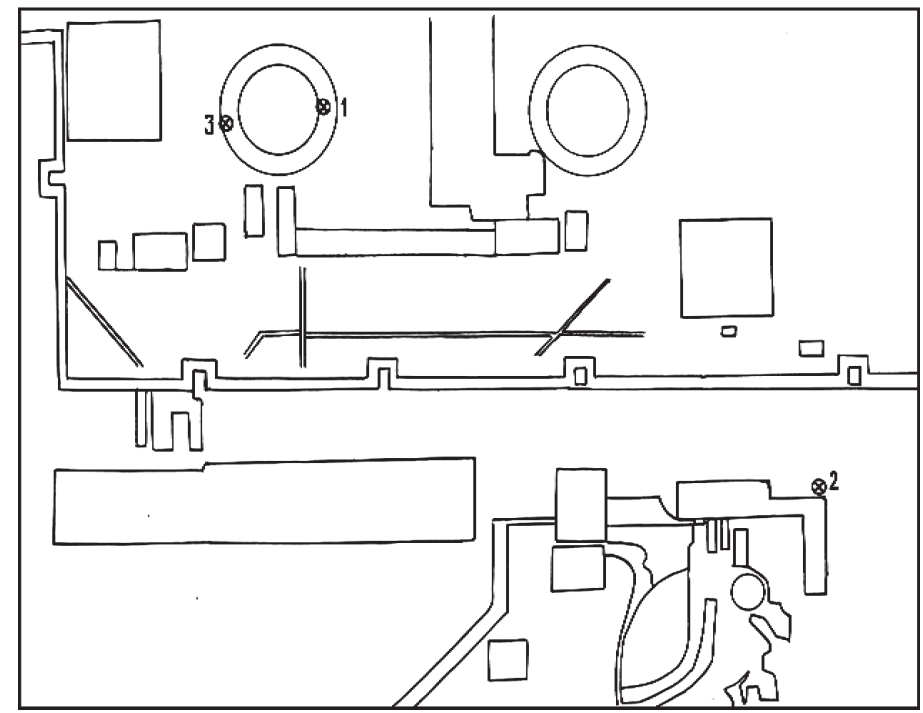

Рис. 1. Схема размещения пунктов

инструментальных сейсмологических наблюдений на площадке Южно-Украинской АЭС:

1 - купол реакторного отделения (РО-1) блока № 1 ;

2 - бомбоубежище (эталонный пункт); 3 - нулевая отметка цоколя РО-1

2, 3 ЮУАЕС моделировалось на основании инженерногеологических и гидрогеологических исследований по результатам бурения скважин.

Эпицентры землетрясений отмечены только в пределах Днестровской зоны возможных очагов землетрясения (ВО3), в районе северной ветви Первомайского разлома и в зоне ступенчатых разломов, заключенных между Одесско-Тальновским разломом и северной (меридиональной) ветвью Первомайского разлома. Ни в одной из остальных выделенных потенциальных сейсмотектонических зон не отмечено проявлений исторических землетрясений, инструментально зарегистрированных землетрясений, сейсмодислокаций. Поэтому на данный момент все выявленные сейсмотектонические зоны района расположения ЮУАЭС могут быть отнесены к классу только потенциально сейсмоопасных. Ближайшей к площадке энергокомплекса потенциальной зоной ВОЗ является северный сегмент Первомайской зоны разломов, проходящей к северо-востоку от г. Первомайска. При этом за время инструментальных наблюдений и за исторически обозримый промежуток времени, когда в этом районе стали появляться населенные пункты и административные центры (последние 200-250 лет), проявлений землетрясений в зоне Первомайского разлома не выявлено. Расчетная интенсивность сейсмического воздействия от потенциальной Первомайской зоны ВОЗ при самых неблагоприятных условиях составит на площадке ЮУАЭС около 6 баллов согласно шкале MSK-64.

Для выполнения инструментальных сейсмологических наблюдений (рис. 1) на площадке ЮУАЭС использовались цифровые автоматические комплексы DAS-05, рассчитанные на выполнение наблюдений для решения региональных сейсмологических задач. По своим техническим параметрам такие комплексы позволяют достаточно надежно регистрировать как слабые, неощутимые для людей сейсмические события, так и максимальные колебания в широком частотном диапазоне $(0,02-24$ Гц).

Пункты наблюдений 1, 3 использовались для построения эмпирических передаточных характеристик от грунта 


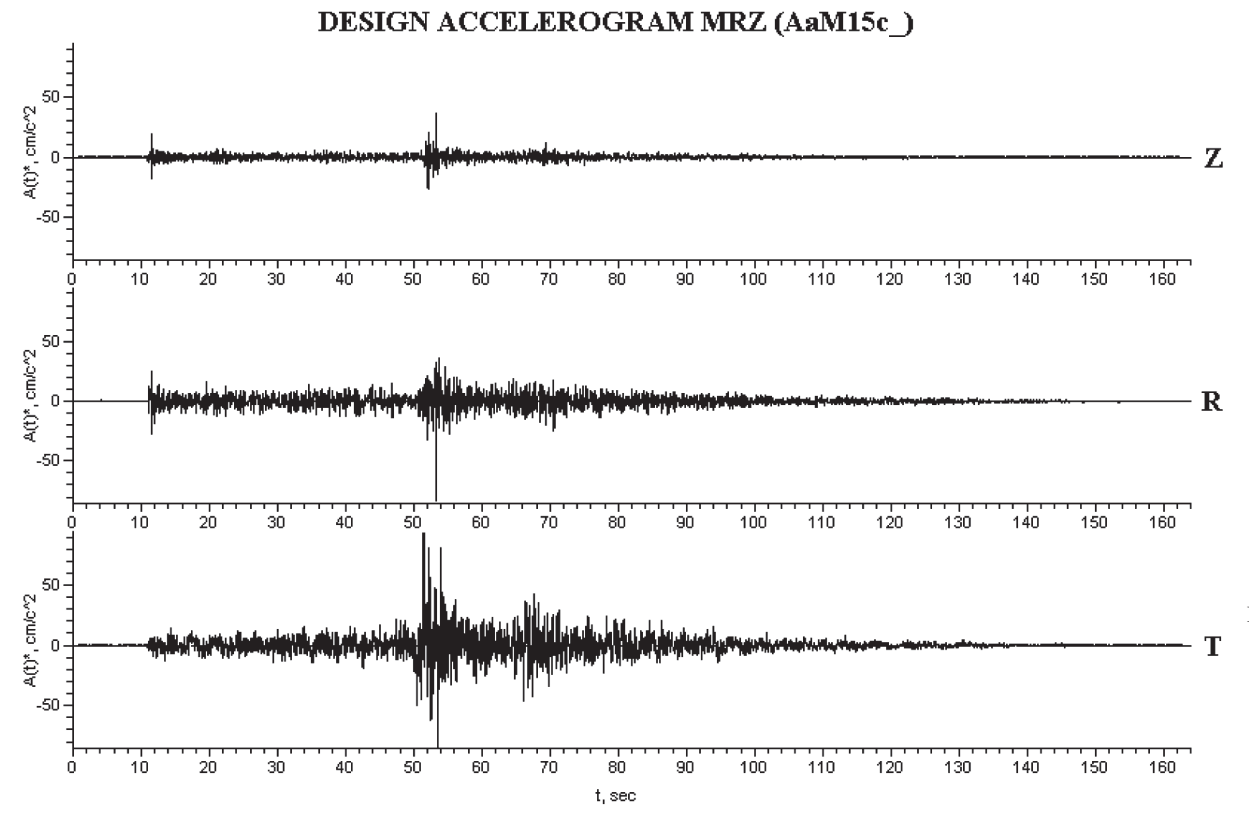

Рис. 2. Пример графика трехкомпонентной расчетной акселерограммы, моделирующей с 83 \%-й обеспеченностью

МР3 из зоны Вранча на свободной поверхности грунта площадки ЮУАЭС, по результатам исследований ИГФ НАНУ [10]

к различным отметкам первого энергоблока ЮУАЭС. Но из-за технических трудностей (высокого уровня колебаний от внутренних источников) от этой идеи пришлось отказаться, так как остановка шумящих агрегатов была невозможной, а сильные землетрясения за период наблюдений не зарегистрированы.

Выносной пункт сейсмологических наблюдений $($ ВПСН) «Щуцкое» был построен и оборудован в 2007 г. в рамках выполнения Программы по созданию системы сейсмологического мониторинга Южно-Украинского энергокомплекса. Пункт оборудован цифровым сейсмографом DAS-03, который по своим техническим характеристикам аналогичен аппаратуре, установленной на площадке Южно-Украинской АЭС.

Надежные характеристики сейсмических событий невозможно получить лишь по записям, сделанным на пунктах временной локальной мониторинговой сети. Поэтому, по возможности, для определения эпицентральных параметров промышленных взрывов, местных и глубокофокусных землетрясений зоны Вранча, дополнительно использовались данные ближних сейсмических станций Карпатской региональной сети, а также апробированная информация международной сейсмологической сети EMSC.

Методика обработки данных подробно описана в [8] и включает в себя следующие основные элементы:

обнаружение и оценку параметров сейсмических событий в реальном времени;

разделение взрывов, местных и удаленных землетрясений.

После детального комплексного анализа полученной информации создан каталог сейсмических событий за период наблюдений, включающий и зарегистрированные промышленные взрывы. В каталоге приведены дата, время возникновения события, его координаты, глубина очага $(H)$ в километрах, магнитуда $(M)$, а также район возникновения 28 землетрясений и 15 взрывов. Местные землетрясения за такой короткий период наблюдений не зарегистрированы. Цифровые записи сейсмических событий использованы для построения акселерограмм землетрясений.
Наиболее полную информацию о величине и характере колебаний грунта на исследуемом участке при будущих (потенциально возможных) максимальных землетрясениях могут дать записи сильных землетрясений из опасных для площадки сейсмогенных зон, зарегистрированных непосредственно на ней (для площадки ЮУАЭС такими могут быть, например, землетрясения из зоны Вранча, находящейся в румынских Карпатах). Но сильные землетрясения, по мощности соизмеримые с проектным землетрясением (П3) и МР3, происходят редко, поэтому получить их записи непосредственно на площадке АЭС за время выполнения работ, как правило, не удается. Для этого нужны постоянно действующие локальные сейсмологические сети. В сложившихся же условиях дефицита наблюденного материала, для моделирования расчетных сейсмических колебаний почвы на площадке Южно-Украинской АЭС были построены синтезированные расчетные акселерограммы, при генерации которых учитывались основные рекомендации МАГАТЭ, включая [9]. При этом комплекс расчетных акселерограмм, моделирующих сейсмические воздействия при ПЗ и МР3 от местных очаговых зон и сейсмоактивной зоны Вранча на поверхности грунта площадки ЮУАЭС, строился с максимальным использованием существующих данных инструментальных сейсмологических наблюдений [8].

Представленные в отчете [10] расчетные акселерограммы (рис. 2) являются функциями времени, моделирующими компоненты вектора ускорений в сейсмических движениях поверхности грунта на площадке ЮУАЭС при землетрясениях, которые могут реализоваться на ней один раз в 100 лет для П3 и один раз в 10000 лет для МР3 с вероятностью непревышения расчетных ускорений $83 \%$. Параметры землетрясений из зоны Вранча, записи которых использовались для получения расчетных акселерограмм, представлены в табл. 1.

Для генерации синтезированных акселерограмм от различных зон ВО3 влияние грунтовых условий на площадке учитывалось путем использования обобщенных теоретических частотных характеристик моделей геологической среды под площадкой, в виде огибающих набора частотных характеристик, рассчитанных для продольных 
Таблица 1. Использованные для получения расчетных акселерограмм параметры землетрясений зоны Вранча, зарегистрированных в районе Южно-Украинской АЭС

\begin{tabular}{|c|c|c|c|c|c|}
\hline \multirow{2}{*}{$\begin{array}{l}\text { № } \\
\text { п/П }\end{array}$} & \multirow{2}{*}{$\begin{array}{l}\text { Время в очаге } \\
\text { землетрясения }\end{array}$} & \multicolumn{2}{|c|}{$\begin{array}{c}\text { Географические коор } \\
\text { динаты очага }\end{array}$} & \multirow{2}{*}{$\begin{array}{c}\text { Глубина } \\
\text { Н, км }\end{array}$} & \multirow{2}{*}{$\begin{array}{c}\text { Магни- } \\
\text { туда } \\
\text { М }\end{array}$} \\
\hline & & $\phi$ & $\lambda$ & & \\
\hline 1 & 2007/10/30 17:55:59 & 45.5 & 27.6 & 25 & 3.8 \\
\hline 2 & 2008/10/02 14:04:50 & 45.7 & 26.5 & 150 & 3.7 \\
\hline 3 & 2008/10/20 11:03:05 & 45.9 & 26.9 & 90 & 3.5 \\
\hline 4 & 2009/10/22 12:20:57 & 45.7 & 26.5 & 157 & 3.7 \\
\hline 5 & 2009/12/05 18:12:30 & 45.8 & 26.8 & 100 & 3.3 \\
\hline 6 & 2009/12/06 20:15:44 & 45.4 & 27.0 & 20 & 3.9 \\
\hline 7 & 2009/12/26 23:04:39 & 45.7 & 26.7 & 100 & 3.6 \\
\hline
\end{tabular}

и поперечных волн в диапазоне углов падения сейсмических волн в пределах 70-90.

По результатам исследований установлено пиковое ускорение грунта при МРЗ на площадке ЮУАЭС на уровне PGA $=0,093 g$ (горизонтальная составляющая сейсмических воздействий).

Результаты исследования площадки ЮУАЭС, изложенные в отчете [8], детально проанализированы ГНТЦ ЯРБ в рамках государственной экспертизы по поручению Госатомрегулирования Украины с привлечением ведущих международных экспертных организаций, таких как Федеральное бюджетное учреждение «Научнотехнический центр по ядерной и радиационной безопасности» (Россия), Институт ядерных исследований «Ржеж» (Чешская Республика) и др. В рамках государственной экспертизы ЯРБ выполнены, в частности:

оценка соответствия представленных материалов требованиям действующих в Украине норм, правил и стандартов в области использования атомной энергетики, а также международным документам и рекомендациям МАГАТЭ, в частности SSG-9 [7];

оценка полноты, корректности и достаточности сведений в представленных материалах.

Основные выводы экспертизы [11] засвидетельствовали, что комплексные исследования в целом выполнены на высоком научно-техническом уровне с учетом рекомендаций МАГАТЭ, однако имеют ряд недостатков:

объем (в части размера территории) и детальность (в части масштаба исследований) работ по району, ближнему району (пункту) и площадке не в полной мере соответствуют рекомендациям МАГАТЭ [7] (в частности, размер исследованного района не достигает радиуса 300 км, а масштаб не соответствует 1:500000);

в работе [8] отсутствуют результаты изучения изменения геологической среды, инженерно-геологических и инженерно-сейсмологических условий размещения ЮУАЭС в процессе ее сооружения и эксплуатации. Недооценка влияния этого фактора создает предпосылки для неопределенности и недостоверности оценок параметров П3 и МР3, что может приводить к некоторой недооценке, в частности, значений максимальных пиковых ускорений на грунте;

в соответствии с [7], продолжительность инструментальных наблюдений должна быть не менее нескольких лет, а наиболее надежные результаты при оценке сейсмической опасности исследуемой площадки можно получить лишь при проведении постоянных сейсмологических наблюдений на специально организованной и оснащенной сети мониторинга и др., что не было сделано при исследовании сейсмичности площадки ЮУАЭС.

Учитывая отмеченные недостатки, с учетом замечаний государственной экспертизы [11], ОП ЮУАЭС было разработано «Концептуальное техническое решение "Об определении сейсмичности площадки ОП ЮУАЭС, сейсмостойкости зданий, оборудования и трубопроводов энергоблока № 1 ОП ЮУАЭС с учетом инженерного запаса», в котором к определенному для площадки ЮУАЭС значению $\mathrm{PGA}_{\mathrm{MP}}=0,093 g$ добавлен $30 \%$-й инженерный запас и значение $\mathrm{PGA}_{\mathrm{MP} 3}$ увеличено до $0,12 g$, что в два раза превысило принятое значение при проектировании энергоблоков станции. Для уточненного значения $\mathrm{PGA}_{\mathrm{MP}}=0,12 g$ ИГФ НАНУ рассчитаны (нормированы) полученные акселерограммы землетрясений от местных источников ВО3 и зоны Вранча, которые в настоящее время используются в качестве исходной сейсмологической информации для переоценки сейсмостойкости зданий, сооружений, оборудования и трубопроводов энергоблоков №№ 1-3 ЮУАЭС.

Ситуация по доисследованиям сейсмической опасности на других площадках АЭС Украины следующая:

аналогичные описанным в данной работе по составу и содержанию исследования завершаются в настоящее время для площадки Запорожской АЭС;

для Хмельницкой и Ровенской АЭС работы по доисследованию сейсмической опасности района и промплощадок выполнены КИИЗИ «ЭнергопроекТ» совместно с ИГФ НАНУ в 1998-2000 гг.

Для ХАЭС и РАЭС в частности выполнены специальные сейсмотектонические и сейсмологические исследования, сейсмическое микрорайонирование площадки, тектономагнитные исследования. В результате построен ансамбль расчетных акселерограмм, моделирующих П3 и МР3 из зоны Вранча и местных очаговых зон. В связи с тем, что для всех синтезированных расчетных акселерограмм, моделирующих МР3 из зоны Вранча и местных зон ВО3, рассчитанные пиковые ускорения МР3 находились в пределах $(0,04 \div 0,08) g$, все рассчитанные акселерограммы для МР3 в соответствии с рекомендациями МАГАТЭ нормировались на значение PGAMP3 $=0,1 g$. Поскольку техническим заданием на выполнение исследований не предусматривался расчет ответных спектров реакции грунтов на данные воздействия, а также расчет поэтажных спектров ответа зданий и сооружений АЭС, такие расчеты не проводились.

Всего по результатам исследований получено: для ХАЭС -8 наборов трехкомпонентных расчетных акселерограмм ПЗ и МР3, моделирующих землетрясения зоны Вранча и 12 наборов акселерограмм для близких очаговых зон; для РАЭС - соответственно по 12 наборов.

Сейсмичность площадок АЭС Украины в будущем требует подтверждения (уточнения) по результатам введения в действие систем постоянного сейсмического мониторинга, предусмотренного мероприятием 18102 КсППБ. 


\section{Выводы}

Результаты воздействия мощных землетрясений на АЭС Японии продемонстрировали, что уровни этих воздействий могут превышать принятые в проекте. Современные требования $\mathrm{K}$ оценке сейсмической опасности площадок атомных станций содержатся в документах МАГАТЭ, в частности [7], и включают: полевые исследования (геолого-тектонические и сейсмологические); построение региональной сейсмотектонической модели; определение максимально возможных уровней колебаний грунта площадок АЭС во время землетрясения. Первой площадкой действующих АЭС Украины, для которой выполнены масштабные исследования ее сейсмической опасности с учетом современной международной практики, стала площадка ЮУАЭС. Исследования выполнялись Институтом геофизики им. С. И. Субботина НАН Украины. С учетом результатов государственной экспертизы материалов этих исследований, пиковое ускорение грунта (PGA) при MP3 площадки ЮУАЭС установлено на уровне $0,12 g$, что в два раза превысило принятое при проектировании станции значение. Сейсмичность площадки ЗАЭС в настоящее время уточняется, а для площадок ХАЭС и РАЭС, на основании имеющихся результатов исследований и с учетом рекомендаций МАГАТЭ, значение PGA при МРЗ принято на уровне $0,1 g$.

В соответствии с рекомендациями МАГАТЭ, продолжительность инструментальных наблюдений должна быть не менее нескольких лет, а наиболее надежные результаты можно получить лишь при проведении постоянных сейсмологических наблюдений по специально организованной и оснащенной сети мониторинга. Комплексной сводной программой повышения уровня безопасности энергоблоков атомных электростанций предусмотрено мероприятие «Внедрение систем сейсмологического мониторинга площадок АЭС» № 18102, в рамках реализации которого до 2016 г. для всех площадок АЭС Украины должны быть выполнены сейсмологические исследования и получены (уточнены) количественные параметры прогнозируемых сейсмических воздействий (пиковые ускорения, акселерограммы землетрясений, спектры ответа грунта), характерные для условий конкретной площадки.

\section{Список использованной литературы}

1. Хмельницкая АЭС. Энергоблок № 2. Технический отчет о результатах работ по доисследованию сейсмической опасности в 3-х томах. - T. I. - Кн. 1: Сейсмотектонические и сейсмологические исследования. - Киев; Симферополь, 2001.

2. Ровенская АЭС. Энергоблок № 4. Технический отчет о результатах работ по доисследованию сейсмической опасности в $3-x$ томах. - T. III. - Кн. 1: Сейсмотектонические и сейсмологические исследования. - Киев; Симферополь, 2001.
3. Convention on Nuclear Safety. National Report of Japan for the Second Extraordinary Meeting, July, 2012.

4. Огляд сучасних міжнародних підходів до сейсмостійкого проектування та оцінки сейсмічної небезпеки енергоблоків АЕС / Д. Ї. Рижов, О-й П. Шугайло, О-р П. Шугайло, Р. Я. Буряк, Л. В. Хамровська, Н Ї. Крицька // Ядерна та радіаційна безпека. 2012. - № 4(56). - C. 23-26.

5. ПНАЭ Г-5-006-87. Нормы проектирования сейсмостойких атомных станций. - Утв. ГАЭН СССР. -1987.

6. Звіт ДНТЦ ЯРБ про науково-дослідну роботу «Розробка вимог до сейсмостійкого проектування та оцінки сейсмічної безпеки енергоблоків АЕС» за договором № 03/7-2011/11-12 від 02.12.11. Аналіз міжнародного досвіду та розробка детального змісту вимог до сейсмостійкого проектування та оцінки сейсмічної безпеки енергоблоків АЕС (проміжний, етап 1).

7. Seismic Hazards in Site Evaluation for Nuclear Installations: Specific Safety Guide No. SSG-9. - Vienna: IAEA, 2010.

8. Южно-Украинский энергокомплекс. Проведение инструментальных наблюдений для уточнения расчетных акселерограмм и пиковых ускорений на поверхности грунта площадки ОП ЮУ АЭС: Отчет ИГФ НАН Украины. - Киев; Львов; Симферополь, 2011. $-87 \mathrm{c}$

9. Evaluation of Seismic Hazards for Nuclear Power Plants. Safety Guide No. NS-G-3.3. - Vienna: IAEA, 2002.

10. Южно-Украинский энергокомплекс. Получение расчетных акселерограмм, пиковых ускорений для проектного землетрясения (ПЗ) и максимального расчетного землетрясения (МР3) на поверхности грунта площадки Ю-У АЭС: Отчет ИГФ НАН Украины. - Киев; Львов; Симферополь, 2011. - 73 с.

11. Звіт ДНТЦ ЯРБ № 11-09-5838 про виконання державної експертизи ядерної та радіаційної безпеки документів ВП ЮУ АЕС «Южно-Украинский энергокомплекс. Отчёт по теме: «Проведение инструментальных наблюдений для уточнения расчётных акселерограмм и пиковых ускорений на поверхности грунта площадки ОП ЮУ АЭС. 04.0.3812.529» та «Южно-Украинский энергокомплекс. Отчёт по теме: «Получение расчётных акселерограмм, пиковых ускорений для проектного землетрясения (ПЗ) и максимального расчётного землетрясения (МР3) на поверхности грунта площадки ЮУ АЭС. 04.0.3812.509». - К., 2011. $-173 \mathrm{c}$ 